\title{
ANALISA KESADARAN BIOPHILIA PADA MAHASISWA CALON PENGGUNA GEDUNG P1 DAN P2 UNIVERSITAS KRISTEN PETRA SURABAYA
}

\author{
Mitha Angreani Subroto ${ }^{1}$, Jimmy Priatman², Jani Rahardjo ${ }^{3}$
}

\begin{abstract}
ABSTRAK: Biophilia adalah ilmu yang mempelajari keinginan manusia untuk berafiliasi dengan bentuk alam dalam kehidupan. Desain biophilik adalah pengembangan biophilia dalam bidang desain ramah lingkungan, menyediakan kesempatan bagi manusia untuk memiliki hubungan dengan alam. Banyak penelitian yang menunjukkan keuntungan dari desain biophilik, salah satunya adanya peningkatan prestasi mahasiswa pada sekolah dengan penerangan alami.
\end{abstract}

Universitas Kristen Petra Surabaya membangun gedung untuk mahasiswa DKV, interior, sastra, dan ilmu komunikasi, dimana mengutamakan konsep ramah lingkungan. Penelitian ini ditujukan untuk mencari analisa kecenderungan biophilia mahasiswa dikaitkan dengan kesadaran terhadap desain biophilik. Penelitian dilakukan dengan menyebarkan kuesioner pada mahasiswa, mencari korelasi antara kesadaran biophilia dengan desain biophilik.

Hasil penelitian menunjukkan tidak ada perbedaan kesadaran biophilia bagi mahasiswa DKV, interior, sastra, dan ilmu komunikasi, maupun berdasarkan angkatan, suku, maupun pengeluaran tiap bulan. Tidak diperlukan adanya perbedaan desain secara spesifik pada jurusan masing-masing. Namun, terdapat beberapa aspek desain yang harus ditingkatkan untuk menciptakan kesadaran biophilia yang lebih tinggi.

Kata kunci : green building, kesadaran biophilia, desain biophilik, studi kasus, kuesioner, Universitas Kristen Petra

\section{PENDAHULUAN}

Manusia memiliki suatu hubungan dengan alam yang merupakan bawaan alami mendasar dalam hidup mereka. Hubungan ini pertama kali ditemukan oleh seorang psikolog bernama Enrich Fromm pada tahun 1964. Istilah biophilia ini mulai dipopulerkan oleh seorang pakar biologi yang bernama Edward O. Wilson di tahun 1984, yang menjelaskan biophilia sebagai suatu dorongan yang dimiliki oleh manusia untuk berafiliasi dengan bentuk-bentuk kehidupan ("mencintai kehidupan"). Biophilia mempelajari tentang manusia yang secara alami memiliki kebutuhan untuk melakukan kontak dengan alam dalam seluruh aspek kehidupan mereka. Tujuan dari biophilia adalah untuk membantu manusia mencapai suatu kesejahteraan dan kenyamanan, serta untuk meningkatkan kualitas hidup mereka. Desain biophilik adalah desain yang menyediakan kesempatan bagi manusia untuk hidup dan bekerja pada tempat yang sehat, minimum tingkat stres, serta menyediakan kehidupan yang sejahtera dengan cara mengintegrasikan alam, baik dengan material alami maupun bentuk-bentuk alami kedalam desain (Browning, Ryan, \& Clancy, 2014).

\footnotetext{
${ }^{1}$ Mahasiswa Program Studi Magister Teknik Sipil Universitas Kristen Petra, mitha.ang@gmail.com

2 Dosen Program Studi Magister Teknik Sipil Universitas Kristen Petra, jpriatman@yahoo.com

${ }^{3}$ Dosen Program Studi Magister Teknik Sipil Universitas Kristen Petra, jani@petra.ac.id
} 
Pada penelitian-penelitian sebelumnya, banyak membuktikan adanya keuntungankeuntungan dengan penerapan desain biophilik pada beberapa public building seperti di rumah sakit, sekolah, kantor, hingga shopping mall (Priatman, 2012). Dari penelitianpenelitian tersebut belum ada secara spesifik penelitian biophilia dikaitkan dengan penerapan desain biophilik ke dalam bangunan kampus atau universitas. Oleh karena itu, pada penelitian ini ingin mencari peluang untuk adanya penerapan hal tersebut secara spesifik dengan obyek penelitian gedung baru Universitas Kristen Petra Surabaya.

Universitas Kristen Petra, salah satu lembaga pendidikan di Surabaya, akan membangun sebuah gedung baru yang berlokasi di belakang gedung P, yakni gedung P1 dan P2. Gedung baru yang didesain dengan konsep ramah lingkungan ini nantinya akan ditempati oleh mahasiswa jurusan DKV (Desain Komunikasi Visual), desain interior, sastra, dan ilmu komunikasi. Penelitian ini menganalisa kecenderungan biophilia mahasiswa dikaitkan dengan kesadaran mereka terhadap desain biophilik dengan tujuan dapat menjadi masukan untuk desain dari gedung P1 dan P2, serta mengarah pada peningkatan kualitas proses belajar mengajar pada Universitas Kristen Petra Surabaya.

\section{TINJAUAN PUSTAKA}

Istilah biophilia pertama kali dikenalkan oleh pemenang Pulizer Price, seorang pakar biologi Universitas Harvard, E.O. Wilson di tahun 1984, dari akar kata bahasa Yunani yang berarti "mencintai kehidupan". Biophilia mendefinisikan adanya suatu ikatan instingtif antara manusia sebagai spesies yang responsif pada bentuk bentuk alami, baik dari segi proses maupun bentuk patra-patra dengan sistim kehidupan mereka. Manusia memiliki kecenderungan yang melekat untuk berhubungan dengan alam, baik secara fisik dan emosional, dalam pengembangan intelektual, kesehatan, maupun kesejahteraan hidupnya.

Terdapat sembilan aspek fundamental yang mewakili penilaian dasar manusia atas hubungan dan kecintaannya terhadap alam (Kellert, 2005). Aspek-aspek ini dapat mewakili kecenderungan biophilia setiap individu, antara lain :

- Utilitarian, pemanfaatan alam, eksploitasi alam secara positif dalam hal materi.

- Naturalistic, alam sebagai sumber stimulasi, detail, dan keberagaman.

- Ecologistic / Scientific, alam merupakan sumber dari ilmu pengetahuan.

- Symbolic, pemanfaatan alam untuk mengekspresikan bahasa dan simbol hidup.

- Aesthetic, daya tarik secara fisik dari keindahan alam yang bersifat universal.

- Negativistic, perasaan takut, enggan, maupun merasa asing terhadap alam.

- Humanistic, ikatan "cinta" dengan alam.

- Moralistici, fokus etika terhadap alam.

- Dominionistic, penguasaan terhadap alam.

Sembilan nilai biophilia ini memiliki peranan yang sama besarnya pada diri manusia. Intensitas nilai tersebut harus seimbang dan tidak boleh saling meniadakan. Jika ada salah satu nilai yang lebih besar porsinya maka dapat menyebabkan menghilangnya nilai-nilai yang lain. (Kellert \& Wilson, 1993)

Desain biophilik adalah desain yang berlandaskan pada aspek biophilia dengan tujuan untuk menghasilkan suatu ruang yang dapat berpartisipasi dalam peningkatan kesejahteraan hidup manusia secara fisik dan mental dengan membina hubungan positif antara manusia dan alam di tempat-tempat yang memiliki makna budaya dan ekologi. Desain biophilik dapat menciptakan ruang-ruang yang restoratif bagi fisik manusia, menyehatkan sistem syaraf, dan menampilkan vitalitas kehidupan yang estetik. Pemenuhan kebutuhan fisiologis manusia (kenyamanan) melalui pendekatan desain bioklimatik, sedangkan pemenuhan kebutuhan psikologis manusia (kesehatan dan ketenangan) melalui pendekatan desain biophilik. (Priatman, 2012). Secara khusus, beberapa point dalam penilaian desain yang dikeluarkan oleh GBCl (Green Building Council Indonesia) berkaitan dengan desain biophilik. 
Pengembangan lahan tepat guna, konservasi dan efisiensi energi, serta kenyamanan dan kesehatan dalam ruang adalah point-point yang mengandung makna dan tujuan dari desain biophilik itu sendiri (Green Building Council Indonesia, 2010).

Banyak fakta penelitian yang telah membuktikan keuntungan-keuntungan yang dapat terjadi dari penerapan desain biophilik, antara lain :

- Ruang pasien dengan view ke alam telah dibuktikan dapat menyebabkan tingkat pemulihan yang lebih cepat (Ulrich, 1984).

- Masa rawat pasien lebih pendek pada ruang rawat dengan adanya akses matahari langsung (Beauchemin \& Hays, 1996).

- Prestasi belajar anak-anak meningkat $20-26 \%$ pada sekolah yang berpenerangan alami (Nicklas \& Bailey, 1996).

- Peningkatan proses belajar mengajar pada sekolah Fort Collins, Seattle sebesar $20 \%$ (Loisos, 1999)

- Shopping mall dengan adanya penghijauan indoor berpotensi meningkatkan penjualan 15\%-20\% (Wolf, 2005).

- Kantor yang minim penerangan alami dan ventilasi berpotensi untuk meningkatkan hormon stres diiringi dengan risiko penyakit jantung (Thayer, et al, 2010).

Desain biophilik dikategorikan menjadi 3 kategori untuk memahami hubungan antara keberagaman alam dengan lingkungan yang berkembang (Browning, Ryan, \& Clancy, 2014), antara lain :

a. Nature in the Space

Memerlukan koneksi secara langsung terhadap berbagai elemen natural, khususnya melalui keberagaman alam, pergerakan, dan interaksi beberapa indera. Terdapat 7 parameter desain dalam kategori ini :

1. Koneksi visual dengan alam.

2. Koneksi non-visual dengan alam.

3. Sensor stimuli non-ritmik.

4. Thermal dan variasi aliran udara.

5. Air.

6. Cahaya yang dinamis dan tersebar.

7. Koneksi antar sistem natural.

b. Natural Analogues

Kategori ini membahas tentang kehadiran alam secara organik dan tidak hidup dengan menyediakan berbagai informasi tentang alam yang terorganisasi dengan baik. Terdapat 3 parameter desain dalam kategori ini, antara lain :

8. Bentuk dan Patra Biomorphic.

9. Koneksi material dengan alam.

10. Kompleksitas dan Keteraturan.

c. Nature of the Space

Pada kategori ini menekankan pada konfigurasi ruang dalam alam, termasuk keinginan bawaan untuk mempelajari alam, dapat melihat melampaui lingkungan sekitar, mengidentifikasi suatu hal berbahaya pada alam atau yang tidak diketahui, maupun fobia terhadap hal-hal tertentu diluar kepercayaan. Terdapat 4 parameter desain dalam kategori ini, antara lain :

11. Prospect. Pandangan jarak jauh tanpa halangan, untuk tujuan pengawasan maupun perencanaan.

12. Refuge. Suatu tempat untuk menghindarkan diri dari lingkungan, terutama suatu kegiatan di lingkungan, dimana individu akan merasa terlindungi dari belakang secara keseluruhan.

13. Misteri.

14. Resiko / Bahaya. 


\section{METODOLOGI PENELITIAN}

Berikut adalah kerangka penelitian yang akan dilakukan yang dapat dilihat pada Gambar 1:

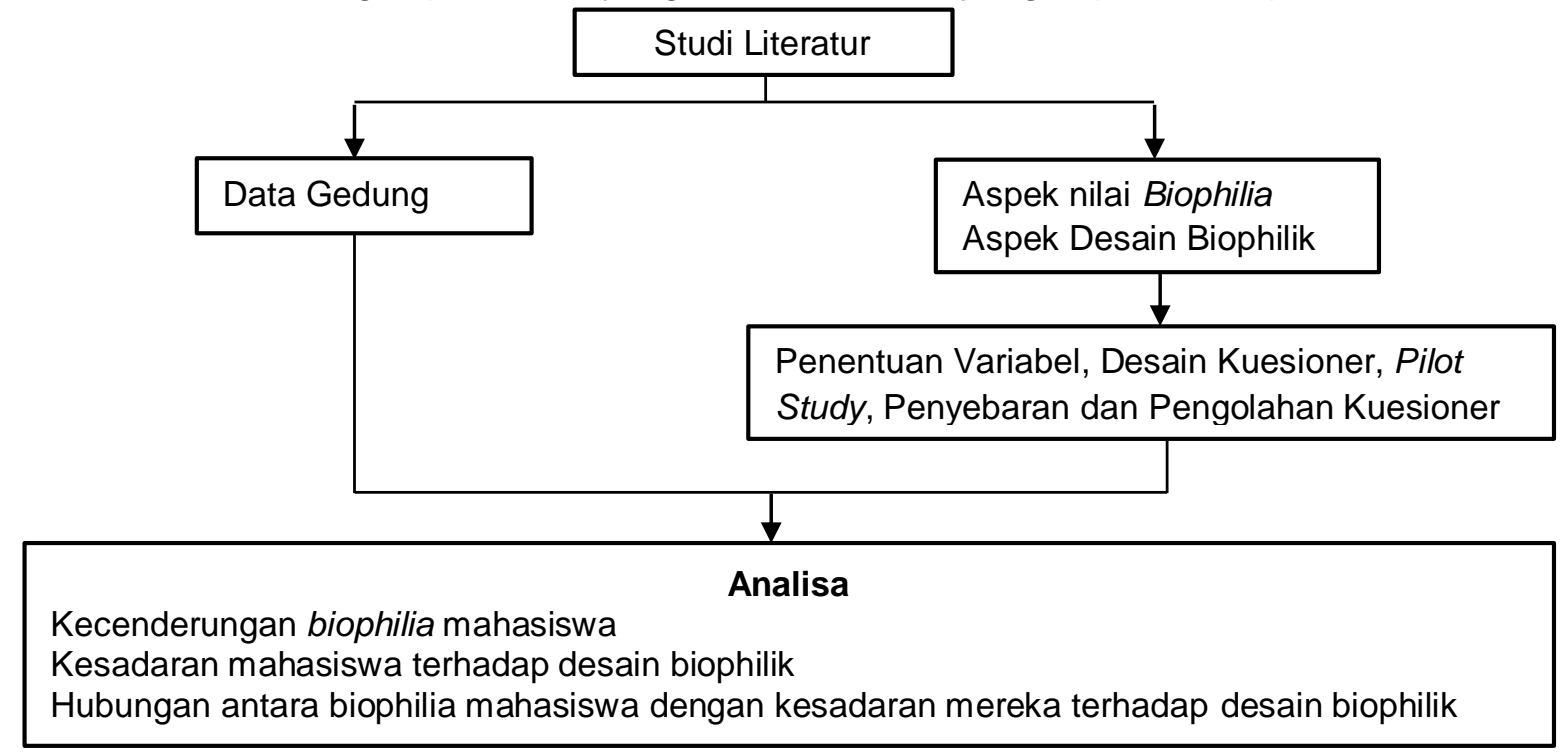

Gambar 1. Kerangka Penelitian

Variabel penelitian yang digunakan adalah sembilan aspek biophilia dan empat belas kriteria desain biophilik. Penelitian kecenderungan biophilia dilakukan secara individual terhadap mahasiswa serta berkelompok disesuaikan dengan klasifikasi responden. Klasifikasi responden terbagi atas angkatan studi, gender, suku, dan pengeluaran tiap bulan. Studi kasus pada penelitian ini adalah gedung P1 dan P2 Universitas Kristen Petra Surabaya. Bangunan ini dirancang dengan mengutamakan konsep bangunan ramah lingkungan.

Metode analisa data diawali dengan uji validitas dan reabilitas untuk menguji validasi dan kehandalan kuesioner yang digunakan. Penguraian hasil kuesioner menggunakan analisa deskriptif dengan bantuan analisa frekuensi dan mean, dilengkapi dengan analisa $t$-test dan anova untuk membandingkan kecenderungan dari dua variabel atau lebih. Analisa korelasi juga digunakan untuk mengetahui korelasi antara sembilan aspek biophilia dengan empat belas kriteria desain biophilik sesuai kebutuhan dan keinginan mahasiswa.

\section{ANALISA DAN PEMBAHASAN}

Total responden dalam penelitian sebanyak 220 mahasiswa yang berasal dari jurusan DKV, interior, ilmu komunikasi, dan sastra. Jumlah responden telah disesuaikan secara proporsional terhadap jumlah mahasiswa keseluruhan di Petra. Angkatan studi responden dipilih mahasiswa yang memiliki kesempatan untuk menempati gedung P1 dan P2, yakni angkatan 2012, 2013, dan 2014.

Analisa awal yang dilakukan adalah melakukan uji validitas dan reabilitas. Dari dua pengujian kehandalan dan kelayakan kuesioner tersebut, tereliminasi beberapa pertanyaan pada variabel negativistic, moralistic, utilitarian, dominionistic, dan humanistic, serta satu pertanyaan dari kategori desain biophilik refuge.

Dari penelitian secara individual, diketahui bahwa rata-rata kesadaran biophilia mahasiswa Petra calon pengguna gedung baru tergolong pada tingkat sedang, yaitu 4.21 dari nilai maksimum 6. Apabila melihat pembagian berdasarkan 9 aspek biophilia, diketahui bahwa terdapat 3 aspek yang dibawah rata-rata, yaitu nilai ecologistic/scientific, naturalistic, dan negativistic. Secara jelas nilai tersebut dapat dilihat pada Gambar 2. 


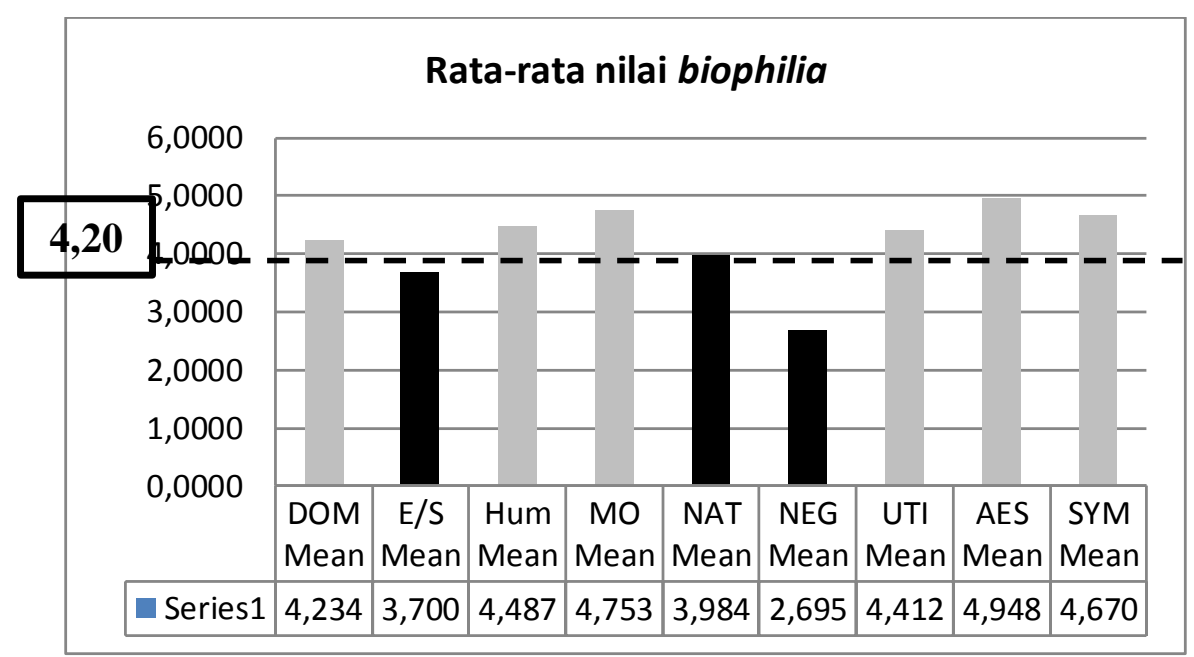

Gambar 2. Diagram Rata-Rata Nilai Biophilia Mahasiswa Responden

Namun, perlu dipastikan tingkat keseragaman dari sembilan aspek biophilia tersebut. Tingkat keseragaman didapat dengan mencari koefisien varian, yaitu dengan membandingkan nilai standard deviasi terhadap rata-rata biophilia tiap mahasiswa dalam setiap aspek biophilia. Koefisien varian yang didapat menunjukkan angka di bawah 1 yang menandakan bahwa tingkat keseragaman rendah. Secara lengkap nilai korfisien varian dapat dilihat pada Tabel 1. Dapat disimpulkan bahwa mahasiswa Petra calon pengguna gedung baru telah memiliki kecenderungan biophilia.

Tabel 1. Nilai Koefisien Varian Setiap Nilai Biophilia

\begin{tabular}{|c|c|c|c|c|}
\hline & $\boldsymbol{N}$ & Mean & Std. Deviation & Coef. of Variance \\
\hline DOM Mean & 220 & 4.2341 & .79113 & 0.187 \\
\hline E/S Mean & 220 & 3.7000 & .77099 & 0.208 \\
\hline Hum Mean & 220 & 4.4879 & .90273 & 0.201 \\
\hline MO Mean & 220 & 4.7538 & .81998 & 0.172 \\
\hline NAT Mean & 220 & 3.9843 & .82113 & 0.206 \\
\hline NEG Mean & 220 & 2.6955 & .84500 & 0.313 \\
\hline UTI Mean & 220 & 4.4127 & .76560 & 0.173 \\
\hline AES Mean & 220 & 4.9489 & .91721 & 0.185 \\
\hline SYM Mean & 220 & 4.6705 & 1.03860 & 0.222 \\
\hline
\end{tabular}

Penelitian selanjutnya dilakukan dengan mencari nilai rata-rata kesadaran dari setiap jurusan, angkatan, jenis kelamin, suku, dan pengeluaran tiap bulan. Berdasarkan klasifikasi jurusan, diketahui jurusan DKV dan sastra memiliki nilai rata-rata tertinggi dibanding jurusan lainnya, mencapai 4.25 dari nilai maksimum 6. Sedangkan jurusan interior dan sastra memiliki nilai rata-rata 4.13. Dari nilai rata-rata tersebut diuji dengan uji anova untuk mengetahui ada tidaknya perbedaan yang signifikan dalam nilai rata-rata tersebut. Hasil dari uji anova diperoleh nilai signifikansi sebesar 0.483 . Hal ini menunjukkan bahwa tidak ada perbedaan antara nilai rata-rata kesadaran biophilia pada keempat jurusan (perbedaan nilai rata-rata dapat diabaikan). Hal yang serupa juga dilakukan pada klasifikasi berdasarkan angkatan, gender, suku, dan pengeluaran tiap bulan. Namun, juga ditemukan tidak adanya perbedaan nilai rata-rata kesadraan biophilia pada masing-masing klasifikasi tersebut.

Untuk selanjutnya dilakukan pengujian yang serupa terhadap variabel yang berbeda, yaitu variabel desain biophilik. Dari penelitian diperoleh nilai rata-rata kesadaran mahasiswa terhadap desain biophilik mencapai 4.72 dari nilai maksimum 6 . Hal ini juga diujikan terhadap 
klasifikasi jurusan, angkatan, gender, suku, dan pengeluaran tiap bulan. Hasilnya juga tidak ditemukan adanya perbedaan rata-rata yang signifikan diantara klasifikasi tersebut.

Setelah mengetahui kecenderungan mahasiswa terhadap biophilia dan kesadaran terhadap aspek desain biophilik, dicari korelasi yang sesuai diantara keduanya, yaitu korelasi antara 9 aspek biophilia terhadap 14 aspek desain biophilik. Hasil dari korelasi ini dipakai untuk meningkatkan aspek biophilia yang nilainya dibawah rata-rata keseluruhan, khususnya pada aspek ecologistic/scientific, naturalistic, dan negativistic.

Dari hasil korelasi, diperoleh bahwa nilai ecologist/scientific akan meningkat seiring dengan adanya elemen desain yang memicu terjadinya koneksi visual antara mahasiswa dengan alam, adanya penggunaan sensor-sensor stimuli non-ritmik, serta didukung dengan adanya kondisi termal dan variasi aliran udara yang baik. Dengan adanya koneksi visual dengan alam, secara langsung dapat memunculkan sensor stimuli non ritmik. Seperti misalnya, dengan mendesain sebuah planter box diisi dengan tanaman yang dapat mengundang datangnya kupu-kupu maupun lebah. Dengan datangnya hewan-hewan tersebut secara alami dapat memberikan sebuah distraksi alami di sela-sela aktivitas mahasiswa agar mereka bisa lebih relaks dan sebagai upaya peregangan. Semakin banyak koneksi manusia dengan alam, semakin dapat memicu naiknya rasa keingintahuan mereka untuk meningkatkan pengetahuan mereka tentang alam maupun melakukan studi terhadap alam.

Nilai naturalistic dapat ditingkatkan dengan memberi kesempatan pada mahasiswa untuk berhubungan dengan alam secara non-visual, didukung juga dengan adanya sensor stimuli non-ritmik dari alam, serta kondisi termal dan variasi aliran udara yang baik. Dengan kata lain, upaya untuk meningkatkan nilai naturalistic pada mahasiswa dapat dilakukan dengan menunjukkan keterlibatan maupun performa alam dalam kehidupan mereka. Seiring dengan besarnya performa alam mempengaruhi kehidupan mahasiswa, maka semakin besar nilai kesadaran mahasiswa bahwa alam merupakan sumber stimulasi, detail, dan keragaman yang dapat mempengaruhi kehidupan mereka.

Nilai negativistic dari mahasiswa akan meningkat apabila mereka memiliki lingkungan dimana koneksi antar sistem natural dalam lingkungan tersebut jelas, serta mereka mempunyai keleluasaan untuk melihat jarak jauh (jarak bebas pandang), namun, tetap harus memiliki suatu area untuk bernaung yang membedakan posisi dirinya di dalam alam agar tidak merasa terlalu "terbuka". Dengan memahami koneksi antar sistem natural yang ada dapat meningkatkan perasaan kedekatan manusia dengan alam. Ditambah dengan pengalaman mereka untuk melihat lebih jauh ke alam dengan pandangan yang lebih bebas, tidak dihalanghalangi baik secara sengaja maupun tidak sengaja juga mendukung hal tersebut. Namun, mengingat nilai negativistic yang terjadi cukup rendah, lebih baik apabila hubungan ekspos dengan alam masih dijaga dengan adanya batasan-batasan yang dapat melindungi manusia, memunculkan perasaan aman walau mereka secara tidak langsung sedang berkoneksi dengan alam.

Jika melihat desain gedung P1 dan P2 Universitas Kristen Petra, ditindaklanjuti berdasarkan hasil penelitian, maka dapat terlihat bahwa desain sudah sesuai dengan kebutuhan dari mahasiswa calon pengguna, dimana tidak diperlukan adanya perbedaan desain secara spesifik disesuaikan dengan jurusan maupun latar belakang lainnya. Hanya saja, jika ingin lebih meningkatkan kesadaran mahasiswa terhadap biophilia, diperlukan tambahan upaya agar nilai rata-rata dari 3 aspek yang masih di bawah rata-rata bisa menjadi lebih tinggi. Contohnya adalah dengan menambahkan green wall sebagai secondary skin pada desain dengan upaya untuk memberikan koneksi visual mahasiswa dengan alam namun tidak melupakan fungsi utama dari secondary skin yaitu untuk mencegah radiasi matahari masuk secara berlebihan kedalam bangunan namun pengguna dari dalam bangunan tetap dapat memiliki jarak pandang yang baik ke luar bangunan. Hal ini merupakan salah satu contoh yang dapat memberikan stimuli mahasiswa untuk meningkatkan nilai ecologistic/scientific 
mahasiswa. Selain itu dengan menambahkan background musik yang bertemakan musikmusik alam yang diputar di area-area yang santai seperti studio maupun koridor juga dapat menjadi stimuli hadirnya koneksi non-visual antara mahasiswa dengan alam. Musik-musik alami seperti suara kicau burung, suara air mengalir, maupun suara angin berhembus dapat memicu meningkatnya nilai naturalistic pada mahasiswa. Begitu halnya dengan mengupayakan menampilkan koneksi antar sistem natural seperti memberikan spot-spot green area berupa roof garden, maupun penambahan wind turbin dan solar panel. Hal ini dapat menyebabkan mahasiswa lebih mengenal alam dan mengurangi perasaan takutnya terhadap alam.

\section{KESIMPULAN DAN SARAN}

Hasil dari penelitian menunjukkan bahwa mahasiswa Petra calon pengguna gedung $\mathrm{P} 1$ dan P2, yaitu mahasiswa jurusan DKV, interior, sastra, dan ilmu komunikasi telah memiliki kesadaran terhadap biophilia. Hal ini terbukti dari adanya keseragaman 9 aspek biophilia yang terungkap dalam koefisien varian yang nilainya kurang dari 1 (tingkat keberagamannya rendah atau seragam). Dengan adanya proporsi nilai yang seragam pada sembilan nilai biophilia tersebut menandakan bahwa mahasiswa responden telah memiliki kesadaran terhadap biophilia. Nilai kesadaran mereka tergolong pada tingkat sedang, yaitu mencapai 4,20 dari nilai maksimum 6 . Selain itu, mahasiswa Petra calon pengguna gedung baru juga telah memiliki kesadaran terhadap desain biophilik. Hal ini terbukti dari nilai rata-rata kesadaran secara keseluruhan mereka sebesar 4,72 dari nilai maksimum 6 .

Tidak ditemukan adanya perbedaan kesadaran dan kecenderungan biophilia dan desain biophilik berdasarkan jurusan, angkatan, gender, suku atau ras, maupun pengeluaran tiap bulan dari responden. Secara statistik, rata-rata kesadaran mereka berdasarkan penggolongan-penggolongan tersebut adalah sama. Maka dapat disimpulkan bahwa latar belakang jurusan responden tidak mempengaruhi kesadaran biophilia mereka.

Hasil korelasi dari sembilan nilai biophilia dengan empat belas aspek desain biophilik menunjukkan bahwa masing-masing nilai memiliki korelasi terhadap stimulasi desain tertentu. Pada penelitian ditemukan adanya nilai-nilai biophilia yang dibawah rata-rata dan memiliki peluang untuk di tingkatkan dengan memberikan stimulasi melalui desain arsitektural, antara lain :

- Nilai ecologist/scientific akan meningkat seiring dengan adanya elemen desain yang memicu terjadinya koneksi visual antara mahasiswa dengan alam, adanya penggunaan sensor-sensor stimuli non-ritmik, serta didukung dengan kondisi termal dan variasi aliran udara yang baik.

- Nilai naturalistic dapat ditingkatkan dengan memberi kesempatan pada mahasiswa untuk berhubungan dengan alam secara non-visual, didukung juga dengan adanya kondisi termal dan variasi aliran udara yang baik, serta memberikan sensor stimuli non-ritmik dari alam kepada mahasiswa.

- Nilai negativistic dari mahasiswa akan meningkat apabila mereka memiliki lingkungan dimana koneksi antar sistem natural dalam lingkungan tersebut jelas, serta mereka mempunyai keleluasaan untuk melihat jarak jauh (jarak bebas pandang), namun, tetap harus memiliki suatu area untuk bernaung yang membedakan posisi dirinya di dalam alam agar tidak merasa terlalu "terbuka".

Dengan menampilkan aspek desain sesuai hasil dari korelasi antara biophilia dan desain biophilik pada desain gedung P1 dan P2, nilai biophilia pada mahasiswa dapat ditingkatkan. Pada dasarnya, desain gedung P1 dan P2 telah memperhatikan konteks lingkungan, mengingat tujuan utama dari perencana adalah ingin menciptakan suatu gedung berbasis ramah lingkungan. Oleh karena itu, dengan adanya realisasi desain pada mahasiswa dapat membuat hubungan mahasiswa dengan alam menjadi lebih erat sehingga dapat meningkatkan kualitas hidup dari masyarakat Petra. 
Pada penelitian selanjutnya sebagai pengembangan penelitian dapat dilakukan terhadap responden dari jurusan selain jurusan DKV, interior, sastra, dan ilmu komunikasi untuk menggali lebih jauh karakteristik kesadaran biophilia responden. Hal tersebut guna mencari faktor-faktor yang mempengaruhi kesadaran biophilia lebih detail. Penelitian juga dapat dikembangkan untuk mencari kualitas view yang diharapkan mahasiswa yang bersangkutan.

\section{DAFTAR REFERENSI}

Beauchemin, K. M., \& Hays, P. (1996). Sunny Hospital Rooms Expedite Recovery from Severe and Refractory Depressions. Journal of Affective Disorders, 40(3), 49-51.

Browning, W., Ryan, C., \& Clancy, J. (2014, October). 14 Patterns of Biophilic Design. Terrapin Bright Green, LLC, 1-60.

Green Building Council Indonesia (2010), Greenship Perangkat Penilaian Bangunan Hijau di Indonesia untuk Bangunan Baru Gedung Komersial. GBCl Jakarta.

Kellert, S. R. (2005). Building for Life: Designing and Understanding the Human-Nature Connection. Island Press, Washington DC.

Kellert, S. R., \& Wilson, E. O. (1993). Biophilia, Biophobia, and Natural Landscapes. In the Biophilia Hypothesis (pp. 73-137).

Loisos, George. (1999). Daylighting in Schools. Heschong Mahone Group,139-145

Nicklas, M., \& Bailey, G. (1996). Energy Performance of Daylit Schools in North Calorina. Energy Performance of Daylit Schools (pp. 1-5). Raleigh, North Carolina.

Priatman, J. (2012). "Konsep Desain Biophilia" sebagai Dimensi Hijau pada Arsitektur Empatik. In Seminar Nasional Menuju Arsitektur Berempati (pp. 35-45).

Thayer, Julian F. et al (2010). Effects of the Physical Work Environment on Physiological Measures of Stress. The European Society of Cardiology.

Ulrich, R. S. (1984). View Through A Window May Influence Recovery from Surgery. Science, 224(4647), 420-421.

Wolf, K. L. (2005). Business District Streetscapes, Trees, and Consumer Response. Journal of Foresty, 103(8), 396-400. 